\title{
A Simple Approach to Distinguish Classic and Formaldehyde-Free Tannin Based Rigid Foams by ATR FT-IR
}

\author{
Gianluca Tondi, ${ }^{1}$ Martin Link, ${ }^{1}$ Chuan Wei Oo, ${ }^{2}$ and Alexander Petutschnigg ${ }^{1}$ \\ ${ }^{1}$ Forest Products Technology \& Timber Construction Department, Salzburg University of Applied Sciences, \\ 136 a Marktstraße, 5431 Kuchl, Austria \\ ${ }^{2}$ School of Chemical Sciences, Universiti Sains Malaysia (USM), 11800 Penang, Malaysia \\ Correspondence should be addressed to Gianluca Tondi; gianluca.tondi@fh-salzburg.ac.at
}

Received 9 October 2014; Accepted 9 February 2015

Academic Editor: Eugen Culea

Copyright (C) 2015 Gianluca Tondi et al. This is an open access article distributed under the Creative Commons Attribution License, which permits unrestricted use, distribution, and reproduction in any medium, provided the original work is properly cited.

\begin{abstract}
Tannin based rigid foams (TBRFs) have been produced with formaldehyde since 1994. Only recently several methods have been developed in order to produce these foams without using formaldehyde. TBRFs with and without formaldehyde are visually indistinguishable; therefore a method for determining the differences between these foams had to be found. The attenuated total reflectance infrared spectroscopy (ATR FT-IR) investigation of the TBRFs presented in this paper allowed discrimination between the formaldehyde-containing (classic) and formaldehyde-free TBRFs. The spectra of the formaldehyde-free TBRFs, indeed, present decreased band intensity related to the $\mathrm{C}-\mathrm{O}$ stretching vibration of (i) the methylol groups and (ii) the furanic rings. This evidence served to prove the chemical difference between the two TBRFs and explained the slightly higher mechanical properties measured for the classic TBRFs.
\end{abstract}

\section{Introduction}

Tannin based rigid foams (TBRFs) are innovative materials obtained by exploiting the capacity of tannin for undergoing polyaddition reactions and that of furfuryl alcohol to polymerize under acid catalysis [1-3]. These materials have been investigated for many years, but only recently have they been systematically studied and many of their properties have been evaluated [4-7].

The first generation of TBRFs has shown good insulation properties and outstanding resistance against fire but they were produced with around $5 \%$ of formaldehyde, required to keep the network stable at room temperature. This drawback has hindered the development of the foams for industrialization because formaldehyde was the most debated chemical in wood science until it was classified as a carcinogenic molecule by the IARC in 2006 [8].

Therefore, several efforts were made in order to produce $100 \%$ natural foams $[9,10]$ without formaldehyde. It was discovered that, by applying an external energy source, the formaldehyde-free tannin-furanic polymer could cross-link to similar extent and the new material obtained had similar properties to the first generation foams [11-13]. In addition, the new TBRFs had a fully natural profile and they were proven to be suitable for the production of lightweight panels; their mechanical performances are slightly weaker than the formaldehyde-containing TBRFs.

Numerous investigations have been carried out to clarify the chemistry of the tannin-furanic polymers, but only partial information could be achieved [14-17]. On one hand, the flavonoid tannin extracts are constituted of aromatic oligomers variously substituted with hydroxyl groups $[18,19]$ and on the other hand the furanic polymers derived from acid polymerization of furfuryl alcohol present strongly interconnected networks in which the $\pi$-electrons can be involved in unpredictable Diels-Alder reactions [20, 21]. The NMR and the MALDI-TOF studies as well as previous investigations were not able to unscramble the polymerization process completely.

In the present paper, the attenuated total reflectance (ATR) infrared spectroscopy was used to investigate the TBRFs and to discriminate the innovative formaldehyde-free TBRFs from the classic TBRFs produced with formaldehyde. 
TABLE 1: Composition by weight of classic and formaldehyde-free tannin based rigid foams.

\begin{tabular}{lcc}
\hline Chemicals & $\begin{array}{c}\text { Classic TBRFs (\%) } \\
\text { Room temperature }\end{array}$ & $\begin{array}{c}\text { Formaldehyde-free } \\
\text { TBRFs (\%) } \\
\text { Hot press at } 120^{\circ} \mathrm{C}\end{array}$ \\
\hline Mimosa tannin & 47.7 & 52.6 \\
Furfuryl alcohol & 16.7 & 13.1 \\
Formaldehyde & 4.3 & - \\
Blowing agent & 4.8 & 3.5 \\
Acid catalyst & 12.4 & 5.8 \\
Water & 14.1 & 25.0 \\
\hline
\end{tabular}

\section{Experimental}

2.1. Materials. The polymers investigated in the present study were produced with the following chemicals: mimosa tannin (Acacia mearnsii formerly mollissima) extract and furfuryl alcohol, which were kindly provided by Silva Chimica (Italy) and International Furan Chemicals (Holland), respectively. The other chemicals, namely, formaldehyde solution (ca 37\%), diethyl ether (blowing agent), and sulphuric acid (acid catalyst), were supplied by Lactan.

2.2. Polymer Preparation. The mimosa tannin-formaldehyde polymer (TF) was produced by mixing a tannin solution in water $(50 \%)$ with $10 \%$ formaldehyde $(\mathrm{w} / \mathrm{w})$ in a plastic test tube. Some drops of sulphuric acid 30\% were added to adjust the $\mathrm{pH}$ to 2.0. After vigorous mixing, the test tube was sealed with a screw cap and the solution was kept in the oven at $103^{\circ} \mathrm{C}$ for 24 hours. The resulting polymer was crushed in powder and further dried for 2 hours in a ventilated oven at $60^{\circ} \mathrm{C}$.

The polyfurfuryl alcohol (PFA) was prepared by adding a few drops of sulphuric acid $30 \%$ to $2 \mathrm{~g}$ of furfuryl alcohol. The exothermic polymerization reaction took place in a few seconds producing a black polymer. The polymer was then ground and dried for 2 hours at $60^{\circ} \mathrm{C}$.

The classic tannin based rigid foams were produced with formaldehyde at room temperature while the formaldehydefree tannin based rigid foams were produced at $120^{\circ} \mathrm{C}$, heating the sample with the hot plates of a press. The two foams were produced according to the protocols already published elsewhere $[2,10]$. Sulphuric acid $30 \%$ was used instead of ptoluenesulfonic acid (65\%) for the synthesis of the TBRFs. The chemical composition of the two formulations is reported in Table 1.

The TBRFs were cut into small specimens of around $2 \times$ $2 \times 2 \mathrm{~cm}^{3}$ dimension keeping only the core material and successively conditioned at $20^{\circ} \mathrm{C}$ and $65 \%$ m.c. for more than one month. Finally, the foams were crushed in a mortar and kept for 5 minutes in a ventilated oven at $60^{\circ} \mathrm{C}$, before ATR FT-IR investigation.

2.3. ATR FT-IR Spectroscopy. The finely ground powders were analysed with a Frontier FT-IR spectrometer from PerkinElmer equipped with a Miracle diamond ATR unit. The investigations were performed in absorbance with 32 scans in the spectral area between 4000 and $600 \mathrm{~cm}^{-1}$ with a resolution of $4 \mathrm{~cm}^{-1}$. The measurements were repeated 5 times for each batch and the spectra obtained were then elaborated with the software "Unscrambler" by Camo. Baseline correction and vector normalization of the signals were applied before averaging the 5 spectra for each sample.

\section{Results and Discussion}

The classic tannin based rigid foams (classic TBRFs) are copolymers constituted by flavonoid tannin, formaldehyde, and furfuryl alcohol units as monomers. The way in which these monomers are interconnected in the TBRFs is still nebulous. Considering that tannin can copolymerize with formaldehyde and that furfuryl alcohol can homopolymerize to polyfurfuryl alcohol (PFA), the TBRFs can be approached as a combined copolymer between these two basic polymers. Figure 1 shows the ATR FT-IR spectra of tanninformaldehyde polymer (TF), polyfurfuryl alcohol (PFA), and classic tannin based rigid foam (classic TBRF). The specific bands attributed to these spectra are reported in Table 2.

The broad band in the region of 3700 to $3000 \mathrm{~cm}^{-1}$ showed the stretching vibration of the $\mathrm{O}-\mathrm{H}$ groups in the different molecules. Comparing the intensity of this band for the three polymers, PFA contained the lowest amount of $\mathrm{O}-\mathrm{H}$ group since most hydroxyl groups from the furfuryl alcohol monomers were removed via dehydration during the polycondensation reactions to form PFA. The more structured spectrum of the PFA was observed also for other furanic molecules as in Table 2. Burket et al. reported the stretching of $\mathrm{C}-\mathrm{H}$ in complex furanic polymers absorbed at these wavenumbers [22]. Bands at around $2900 \mathrm{~cm}^{-1}$ indicated the presence of saturated $\mathrm{C}-\mathrm{H}$ stretching from the methylene $\left(-\mathrm{CH}_{2}-\right)$, dimethylene ether $\left(-\mathrm{CH}_{2}-\mathrm{O}-\mathrm{CH}_{2}-\right)$, and methylol $\left(-\mathrm{CH}_{2} \mathrm{OH}\right)$ groups in the TF, PFA and classic TBRF. The region between 2500 and $1800 \mathrm{~cm}^{-1}$ does not present significant absorptions except for $\mathrm{CO}_{2}$ and therefore it can be negligible.

At around $1700 \mathrm{~cm}^{-1}$ the $\mathrm{C}=\mathrm{O}$ bond stretching occurs. All the polymers studied present a large band at this wavenumber. The tannin extracts show this peak exclusively after formaldehyde activation [23], while the furanic polymer presents carbonyl groups after furan ring opening for incomplete scission of the ether linkage. The possible structure of PFA with the opened furan ring (Figure 2) has been suggested by Conley and Metil [24]. The presence of this signal in the classic TBRF also meant that carbonyl groups were still available after the reaction was completed.

The absorption at around $1610 \mathrm{~cm}^{-1}$ is very intense for the tannin-containing polymers while being less significant for the polyfurfuryl alcohol. This peak is typically attributed to $\mathrm{C}=\mathrm{C}$ stretching in benzene ring. The formation of the aromatic benzene rings in PFA could occur from the DielsAlder reactions between the furan rings (dienes) in an oligomeric chain and conjugated dihydrofuranic sequences (dienophiles) in another oligomer chain [20]. The Diels-Alder adducts could further undergo aromatization converting the oxygen-bridged bicyclic moiety into the benzene ring (Figure 3). The newly formed benzene rings linked the two 


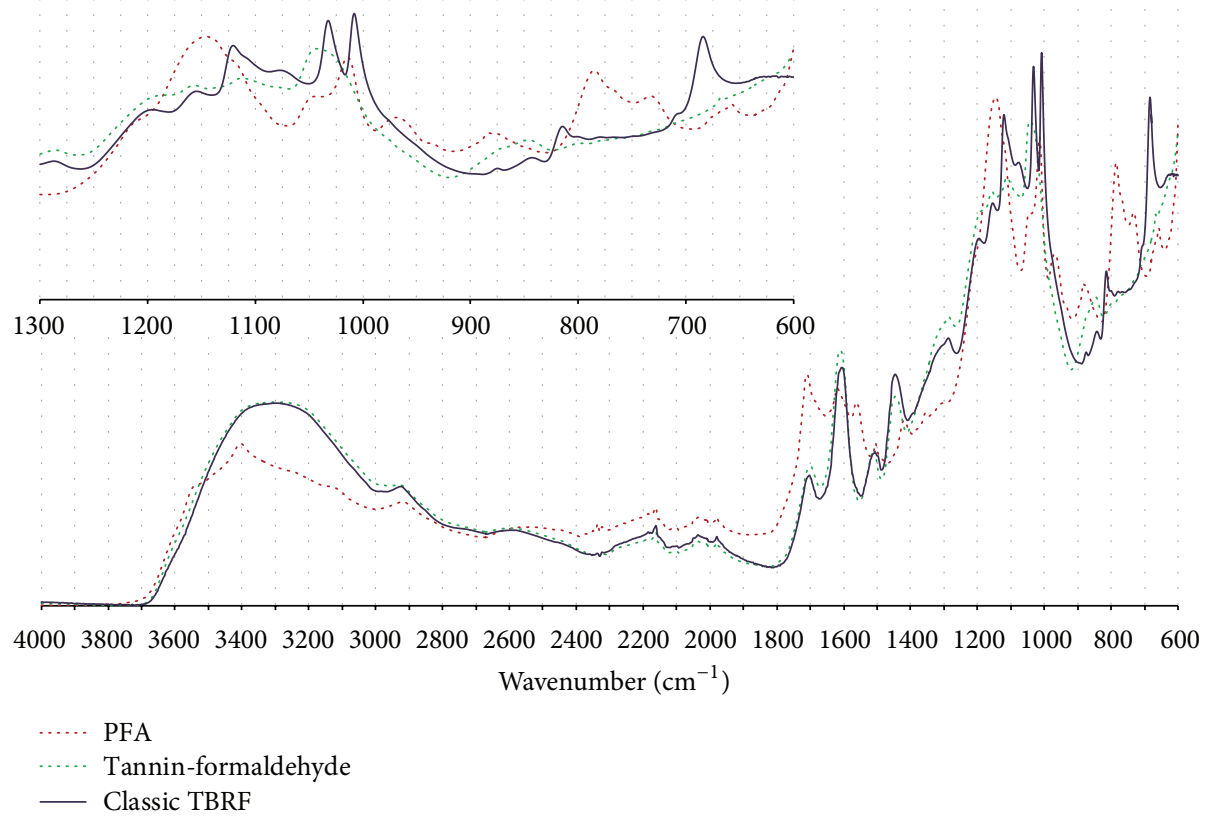

FIGURE 1: ATR FT-IR spectra of polyfurfuryl alcohol (red dot) tannin-formaldehyde polymer (green dots) and classic tannin based rigid foam (dark blue).

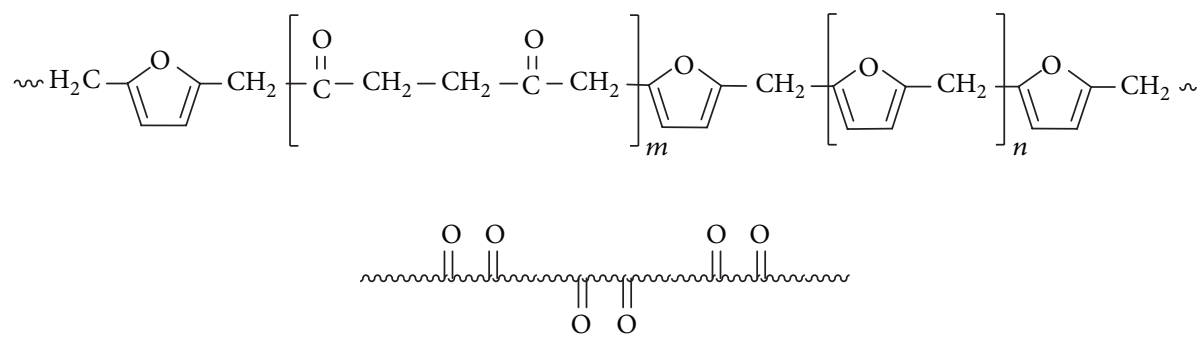

FIGURE 2: Structure of polyfurfuryl alcohol (PFA) with opened furan ring [23].

PFA chains together and enhanced the conjugation of the polymeric system.

The spectral region between 1560 and $1300 \mathrm{~cm}^{-1}$ presents principally in-plane $\mathrm{C}-\mathrm{H}$ bending of aromatic molecules. The heteroaromatic compounds absorb preferentially in the region $1560-1500 \mathrm{~cm}^{-1}$ while the phenolic compounds present major vibrations at around $1450 \mathrm{~cm}^{-1}$.

The region between 1300 and $950 \mathrm{~cm}^{-1}$ (expanded in Figure 1) is strongly dominated by $\mathrm{C}-\mathrm{O}$ stretching vibrations even if a few $\mathrm{O}-\mathrm{H}$ bending and aromatic $\mathrm{C}-\mathrm{H}$ bending vibrations occurred as well. In this region of the spectrum, the classic TBRF presents a slightly different profile from the ones of the two templates polymers. A major disaccording occurred at $1120 \mathrm{~cm}^{-1}$ where the $-\mathrm{C}-\mathrm{O}-\mathrm{C}$ - stretching signal takes place. This band shows higher intensity due to the increasing amount of ether bridges in the TBRF. This assumption could be confirmed noticing the increase of the bands at around 1035 and $1010 \mathrm{~cm}^{-1}$. These bands could be attributed to $\mathrm{C}-\mathrm{O}$ vibrations of (i) $-\mathrm{C}-\mathrm{O}-\mathrm{C}-$ ether bridges in complex oxygen containing cyclic molecules and/or (ii) $=\mathrm{C}-\mathrm{O}-\mathrm{C}=$ breathing in furanic moieties. The first confirmed the presence of dimethylene-ether bridges obtained by the condensation of two methylol groups, while the second suggested a lower degree of furan ring opening when the PFA polymerized in presence of tannin-formaldehyde at room temperature. It is worth noting that the TF polymerized also via methylol condensation, but due to the drastic polymerization conditions $\left(103^{\circ} \mathrm{C}\right.$ for 24 hours $)$ the higher majority of the dimethylene-ether bridges evolved to methylene bridges by releasing formaldehyde.

In the fingerprint region from 950 to $600 \mathrm{~cm}^{-1}$ the assignments are very complicated but $\mathrm{C}-\mathrm{H}$ bending of aromatic (principally out of plane) occurs with high frequency. This region can give immediate information about the degree of compactness of the polymers. The more the polymer is compactly networked, the less the absorption for out-ofplane vibration will be due to the high steric hindrance. The classic TBRF FT-IR spectrum presents intermediate compactness between TF (highly interconnected) and PFA (less interconnected). Distinct signals between TBRF and the two basic polymers (PFA and TF) could be observed especially at the wavenumbers 780 and $680 \mathrm{~cm}^{-1}$. The strong signal at 


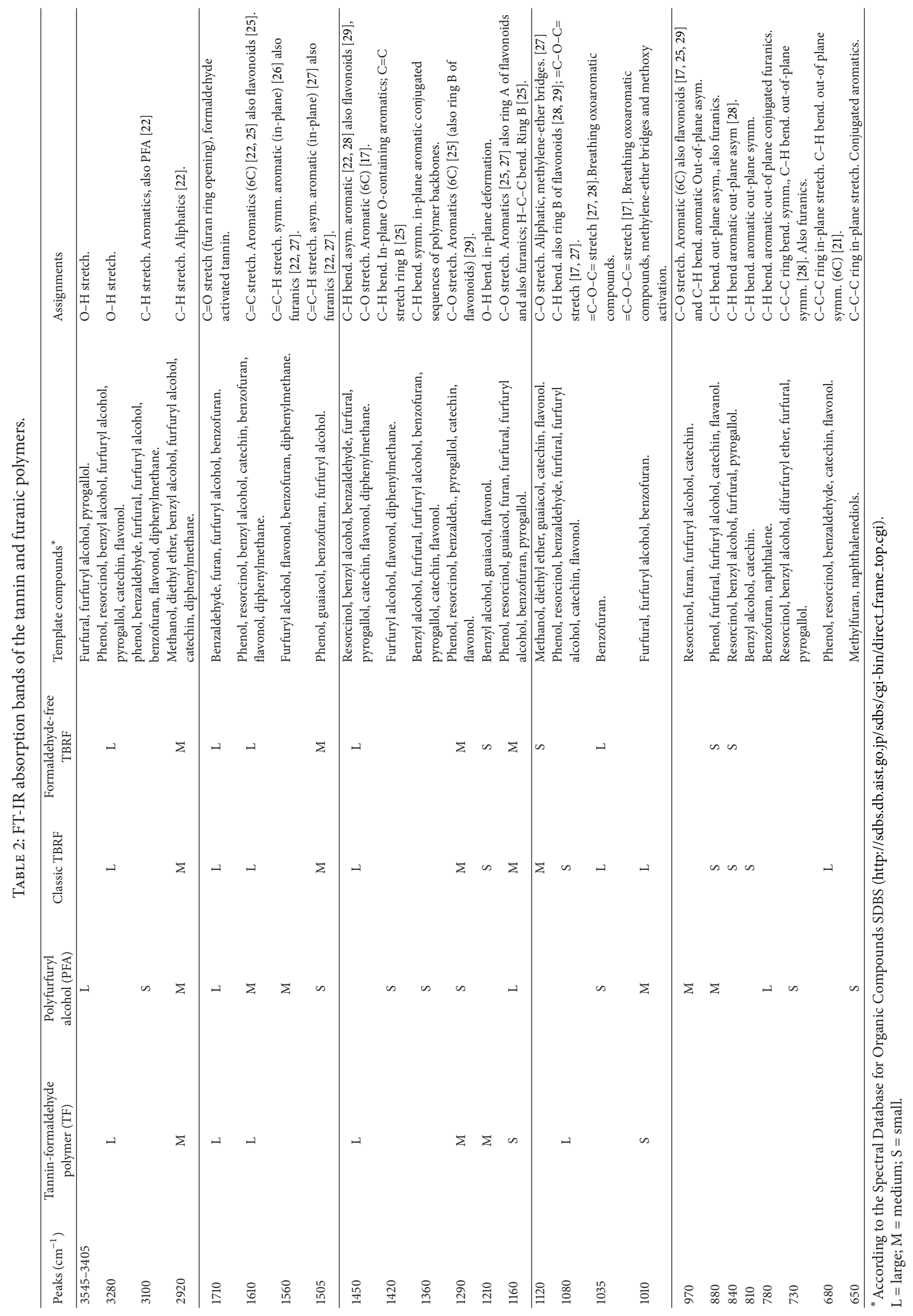




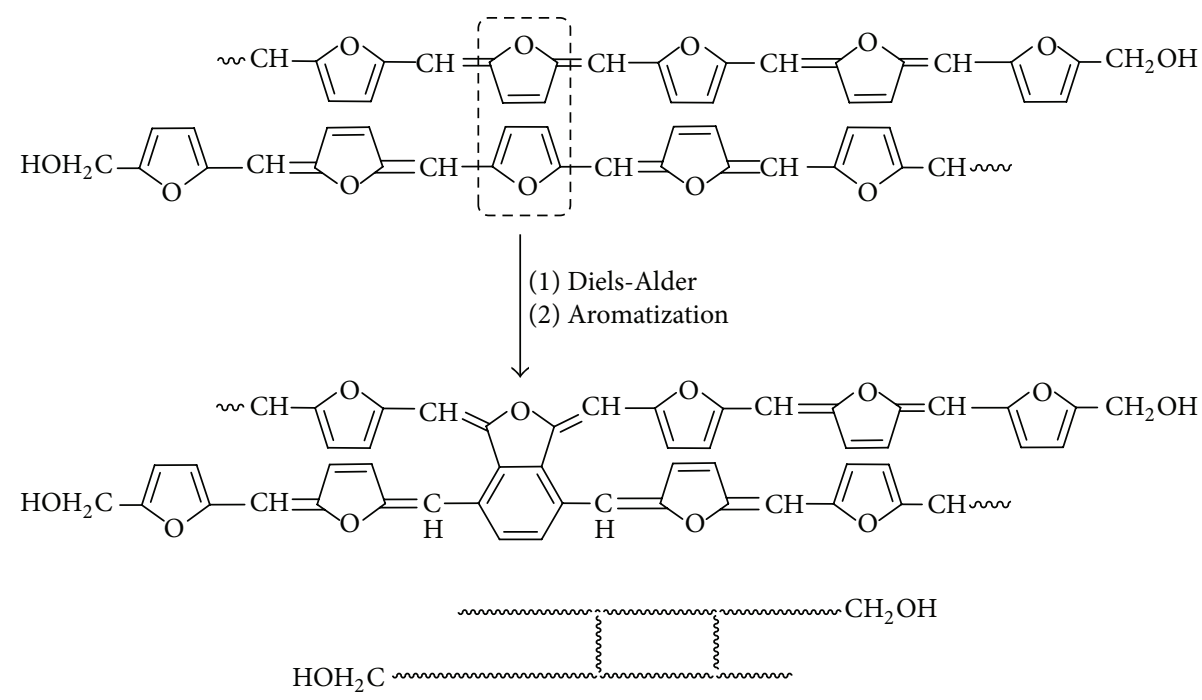

FIGURE 3: Formation of benzene ring via the Diels-Alder and aromatization reactions joining the two polyfurfuryl alcohol chains.

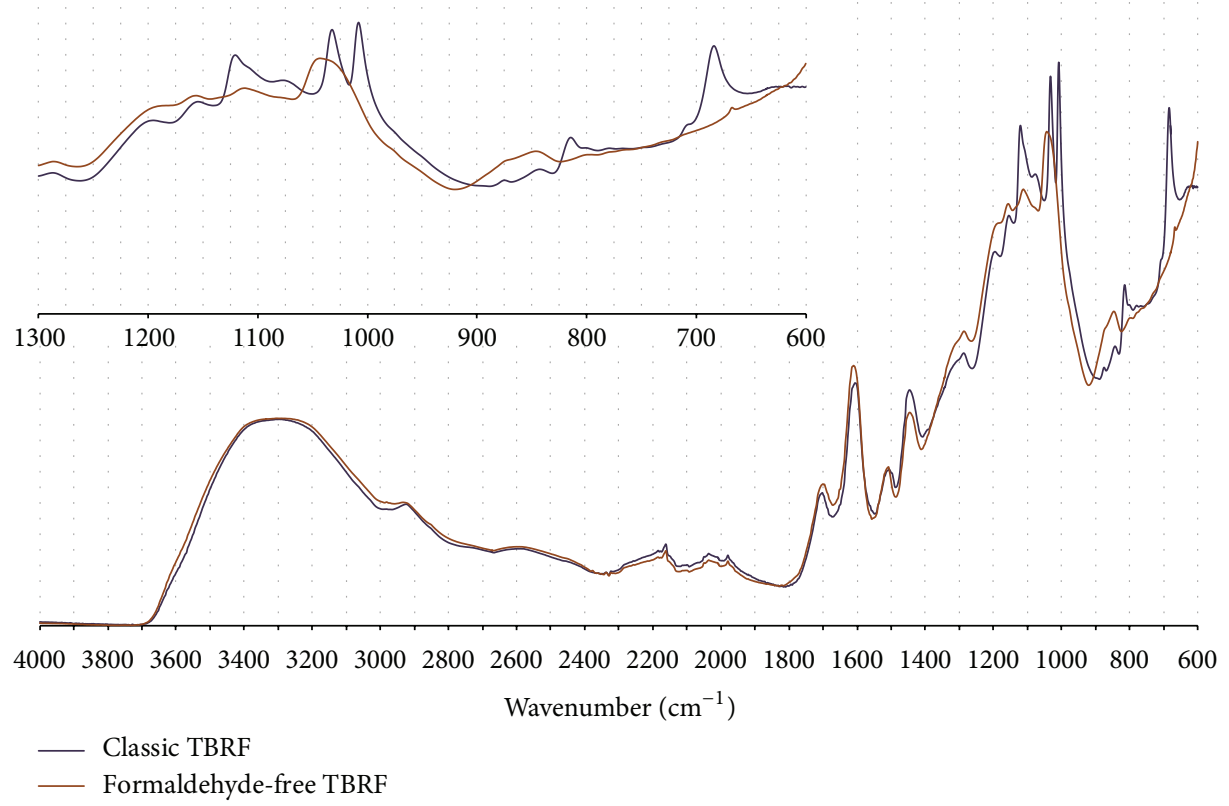

FIGURE 4: ATR FT-IR spectra of classic (blue) and formaldehyde-free (brown) tannin based rigid foam.

$780 \mathrm{~cm}^{-1}$ of PFA which can be attributed to the conjugated polyheteroaromatic furan ring decreased due to the limited amount of ring opening. Classic TBRF showed a strong absorption at $680 \mathrm{~cm}^{-1}$ referring to the $\mathrm{C}-\mathrm{C}-\mathrm{C}$ ring in-plane stretching and $\mathrm{C}-\mathrm{H}$ out-of-plane bending of the benzene rings. Comparing the TF and classic TBRF, some of the tannin-formaldehyde copolymers in classic TBRF were interacted with the terminal methylol groups of PFA (Figure 3) which separated the tannin-formaldehyde copolymers from each other. This orientation reduced the compactness of polymers arrangement in classic TBRF that made the C$\mathrm{C}-\mathrm{C}$ stretching and $\mathrm{C}-\mathrm{H}$ bending occur more easily. The tannin-formaldehyde copolymers in TF, however, had higher compact arrangement that hindered these vibration modes.
PFA also showed small absorption at $680 \mathrm{~cm}^{-1}$ due to the formation of small amount of benzene rings from the DielsAlder and aromatization reactions between the PFA chains.

In summary, the vibrations of the classic TBRF could be obtained as a mix between the tannin-formaldehyde copolymer and the polyfurfuryl alcohol for all over the middle infrared region. It was possible to consider two extreme scenarios: (i) the two basic polymers were not competitive and developed in a parallel way without copolymerizing each other and (ii) the three monomers mixed intimately but maintained the structure similarly arranged to the two basic copolymers. Due to the fact that only a few "partially new" bands were observed $\left(1120,1035\right.$, and $\left.1010 \mathrm{~cm}^{-1}\right)$, it could be more logical to consider scenario (i) as the one occurring 


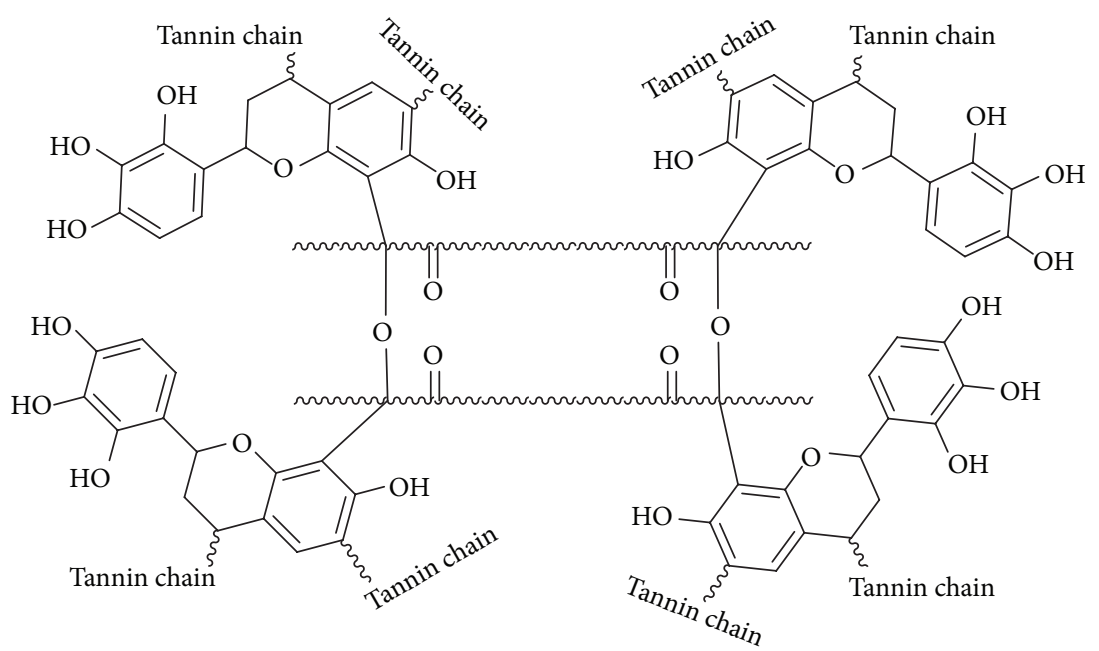

(a)

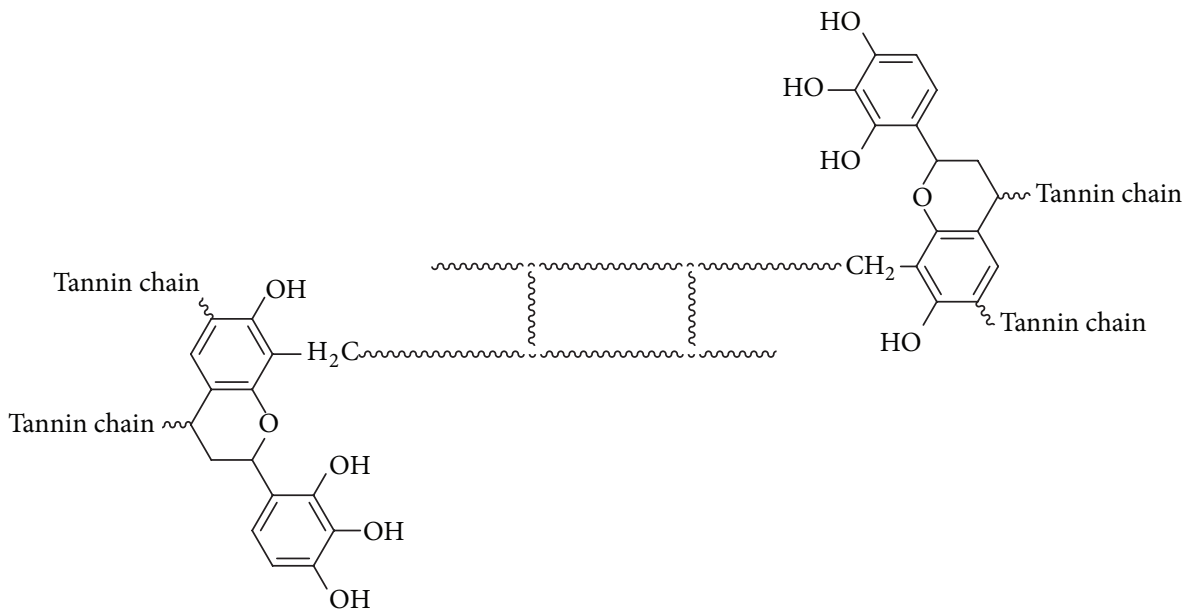

(b)

FIGURE 5: Proposed tannin-furanic interactions in formaldehyde-free TBRF (a) and classic TBRF (b).

to the higher extent. But considering the fast kinetics of the formation of furanic polymers, it is senseful to imagine that a certain amount of tannin molecules incorporated into the network of the polyfurfuryl alcohol can create some covalent bonded tannin-furanic adducts preferentially via dimethylene ether $\left(-\mathrm{CH}_{2}-\mathrm{O}-\mathrm{CH}_{2}-\right)$ bridges. The FT-IR investigation of the tannin foams showed that the MALDI-TOF investigations are mostly confirmed: even if a certain amount of units in which furanics and flavonoids are combined, most of the copolymers are constituted of tannin-formaldehyde or polyfurfuryl alcohol fractions. These considerations become more interesting when formaldehyde-free tannin foams are investigated.

Indeed, when the spectra of classic TBRF and formaldehyde-free TBRF are compared (Figure 4), it is possible to notice that from 4000 until $1200 \mathrm{~cm}^{-1}$ the spectra overlap almost perfectly. Due to the lack of formaldehyde, the signal at $1700 \mathrm{~cm}^{-1}$ could have been significantly decreased for formaldehyde-free TBRF, but no evidence of this phenomenon occurs, because the carboxyl group was predominantly derived from the incomplete scission of the furfuryl alcohol's units.

Conversely, a certain difference takes place in the wavenumber region between 1200 and $600 \mathrm{~cm}^{-1}$. The main difference can be attributed to lack of the band at $1010 \mathrm{~cm}^{-1}$ and the decreasing intensity of the bands at 1120, 1080, 810 , and $680 \mathrm{~cm}^{-1}$ for formaldehyde-free TBRF. The band at $1010 \mathrm{~cm}^{-1}$ could be attributed to the bending of dimethyleneether bridges formed when the tannin reacted with the formaldehyde. This band was strongly decreased in the formaldehyde-free TBRF spectrum. This first observation combined with the decreasing of the band intensity at $1120 \mathrm{~cm}^{-1}$ suggested that dimethylene-ether bridges were strongly diminishing in formaldehyde-free TBRF. The presence of this signal, even if to a small extent, suggested that other ether bridges could occur also from the tannin-furanic interaction as shown in Figure 5(a). Finally further evidence occurring in the formaldehyde-free TBRF is the reduced 
intensity of the band at $1080 \mathrm{~cm}^{-1}$ which corresponds to the $=\mathrm{C}-\mathrm{O}-\mathrm{C}=$ breathing of the furanic ring and suggested that the furfuryl alcohols, when polymerized at higher temperature $\left(120^{\circ} \mathrm{C}\right)$, have a higher tendency to break their ring structure. Much weaker bands at 810 and $680 \mathrm{~cm}^{-1}$ suggested less aromatic $\mathrm{C}-\mathrm{H}$ out-of-plane vibration. This could be due to the more compact tannin-furanic network in formaldehyde-free TBRF which hindered this kind of $\mathrm{C}-\mathrm{H}$ vibration.

Generally, it can be assumed that formaldehyde-free TBRF and classic TBRF present different polymerization systems. For formaldehyde-free TBRF, the furanic rings were more easily opened to reveal the reactive sites ( $\mathrm{C}=\mathrm{O}$ groups), creating certain amount of flavonoid-furan interconnections which were structurally close to each other so that the aromatic parts of the polymer had higher difficulties in vibrating (Figure 5(a)). As for the classic TBRF, the methylol groups of tannin polymers could be reacted with the free hydroxyl groups at both terminal ends of the benzene linked PFA chains giving greater space among the aromatic parts (Figure 5(b)). This molecular arrangement suggested that the formaldehyde-free TBRF was even more brittle and hence less mechanically performing.

\section{Conclusions}

Infrared spectroscopy has shown to be a very good method for the investigation of tannin based rigid foams. In particular it was possible to confirm the MALDI-TOF study for the classic TBRF in which the presence of a majority of tanninformaldehyde and polyfurfuryl alcohol with which only some evidence of simultaneous presence of the three constituents was detected.

The formaldehyde-free TBRF can be discriminated from the classic TBRF by ATR FT-IR spectroscopy. The fingerprint region (between 1200 and $600 \mathrm{~cm}^{-1}$ ) of their FT-IR spectra offered small but significant differences. The higher temperature at which the formaldehyde-free TBRFs were produced allowed more furanic units to open their rings, increasing the amount of branches from the tannin-furanic interactions. Tannin-furanic interactions in formaldehydefree TBRF created more compact polymeric system which involves a more rigid structure compared to the classic TBRF. This evidence explains the weaker mechanical properties of formaldehyde-free TBRF.

\section{Conflict of Interests}

The authors declare that there is no conflict of interests regarding the publication of this paper.

\section{Acknowledgment}

The authors gratefully acknowledge the federal state of Salzburg for its support in the project "Enhancing the Properties of Biogenic Materials for Their Application in Green Building Insulation.”

\section{References}

[1] N. E. Meikleham and A. Pizzi, "Acid- and alkali-catalyzed tannin-based rigid foams," Journal of Applied Polymer Science, vol. 53, no. 11, pp. 1547-1556, 1994.

[2] G. Tondi and A. Pizzi, "Tannin-based rigid foams: characterization and modification," Industrial Crops and Products, vol. 29, no. 2-3, pp. 356-363, 2009.

[3] G. Tondi, W. Zhao, A. Pizzi, G. Du, V. Fierro, and A. Celzard, "Tannin-based rigid foams: a survey of chemical and physical properties," Bioresource Technology, vol. 100, no. 21, pp. 5162$5169,2009$.

[4] G. Tondi, C. W. Oo, A. Pizzi, A. Trosa, and M. F. Thevenon, "Metal adsorption of tannin based rigid foams," Industrial Crops and Products, vol. 29, no. 2-3, pp. 336-340, 2009.

[5] G. Tondi, A. Pizzi, and R. Olives, "Natural tannin-based rigid foams as insulation for doors and wall panels," Maderas: Ciencia y Tecnologia, vol. 10, no. 3, pp. 219-227, 2008.

[6] G. Tondi, M. Johansson, S. Leijonmark, and S. Trey, "Tannin based foams modified to be semi-conductive: synthesis and characterization," Progress in Organic Coatings, vol. 78, pp. 488493, 2015.

[7] G. Tondi, S. Blacher, A. Leonard et al., "X-ray microtomography studies of tannin-derived organic and carbon foams," Microscopy and Microanalysis, vol. 15, no. 5, pp. 384-394, 2009.

[8] IARC, "Formaldehyde, 2-Butoxyethanol and 1-tert-Butoxypropan-2-ol," Group 1, 88, 100F, 2006, http://monographs.iarc.fr/ ENG/Classification/.

[9] M. C. Basso, X. Li, V. Fierro, A. Pizzi, S. Giovando, and A. Celzard, "Green, formaldehyde-free, foams for thermal insulation," Advanced Materials Letters, vol. 2, no. 6, pp. 378-382, 2011.

[10] C. Lacoste, M. C. Basso, A. Pizzi, M.-P. Laborie, D. Garcia, and A. Celzard, "Bioresourced pine tannin/furanic foams with glyoxal and glutaraldehyde," Industrial Crops and Products, vol. 45, pp. 401-405, 2013.

[11] M. Link, C. Kolbitsch, G. Tondi, M. Ebner, S. Wieland, and A. Petutschnigg, "Tannin-based foams for panels," Bioresources, vol. 6, pp. 4218-4228, 2011.

[12] C. Kolbitsch, M. Link, A. Petutschnigg, S. Wieland, and G. Tondi, "Microwave produced tannin-furanic foam," Journal of Materials Research, vol. 1, no. 3, pp. 84-91, 2012.

[13] G. Tondi, M. Link, C. Kolbitsch, and A. Petutschnigg, "Infraredcatalyzed synthesis of tannin-furanic foams," BioResources, vol. 9, no. 1, pp. 984-993, 2014.

[14] G. Tondi, A. Pizzi, H. Pasch, and A. Celzard, "Structure degradation, conservation and rearrangement in the carbonisation of polyflavonoid tannin/furanic rigid foams-a MALDI-TOF investigation," Polymer Degradation and Stability, vol. 93, no. 5, pp. 968-975, 2008.

[15] G. Tondi, A. Pizzi, H. Pasch, A. Celzard, and K. Rode, "MALDIToF investigation of furanic polymer foams before and after carbonization: aromatic rearrangement and surviving furanic structures," European Polymer Journal, vol. 44, no. 9, pp. 29382943,2008

[16] A. Pizzi, G. Tondi, H. Pasch, and A. Celzard, "Matrix-assisted laser desorption/ionization time-of-flight structure determination of complex thermoset networks: polyflavonoid tanninfuranic rigid foams," Journal of Applied Polymer Science, vol. 110, no. 3, pp. 1451-1456, 2008.

[17] A. Reyer, G. Tondi, M. Demker, A. Petutschnigg, and M. Musso, Journal of Raman Spectroscopy, submitted. 
[18] A. Pizzi, "Tannin-based wood adhesives," in Advanced Wood Adhesives Technology, chapter 5, pp. 149-217, Marcel Dekker, New York, NY, USA, 1994.

[19] A. E. Hagerman and L. G. Butler, "Tannins and lignin," in Herbivores, Their Interactions with Secondary Plant Metabolites, chapter 10, pp. 355-383, Academic Press, San Diego, Calif, USA, 1991.

[20] M. Choura, N. M. Belgacem, and A. Gandini, "Acid-catalyzed polycondensation of furfuryl alcohol: mechanisms of chromophore formation and cross-linking," Macromolecules, vol. 29, no. 11, pp. 3839-3850, 1996.

[21] M. Choura, N. M. Belgacem, and A. Gandini, "The acidcatalyzed polycondensation of furfuryl alcohol: old puzzles unravelled," Macromolecular Symposia, vol. 122, no. 1, pp. 263268, 1997.

[22] C. L. Burket, R. Rajagopalan, A. P. Marencic, K. Dronvajjala, and H. C. Foley, "Genesis of porosity in polyfurfuryl alcohol derived nanoporous carbon," Carbon, vol. 44, no. 14, pp. 29572963, 2006.

[23] G. Tondi and A. Petutschnigg, "Middle infrared (ATR FT-MIR) characterization of industrial tannin extracts," Industrial Crops and Products, 2015.

[24] R. T. Conley and I. Metil, "An investigation of the structure of furfuryl alcohol polycondensates with infrared spectroscopy," Journal of Applied Polymer Science, vol. 7, no. 1, pp. 37-52, 1963.

[25] O. Unsalan, Y. Erdogdu, and M. T. Gulluoglu, "FT-Raman and FT-IR spectral and quantum chemical studies on some flavonoid derivatives: baicalein and Naringenin," Journal of Raman Spectroscopy, vol. 40, no. 5, pp. 562-570, 2009.

[26] L. Ping, A. Pizzi, Z. D. Guo, and N. Brosse, "Condensed tannins from grape pomace: characterization by FTIR and MALDI TOF and production of environment friendly wood adhesive," Industrial Crops and Products, vol. 40, no. 1, pp. 13-20, 2012.

[27] C. Song, T. Wang, X. Wang, J. Qiu, and Y. Cao, "Preparation and gas separation properties of poly(furfuryl alcohol)-based C/CMS composite membranes," Separation and Purification Technology, vol. 58, no. 3, pp. 412-418, 2008.

[28] E.-M. A. Ajuong and C. Birkinshaw, "The effects of acetylation on the extractives of Sitka Spruce (Picea sitchensis) and Larch (Larix leptoleptis) wood," Holz als Roh-und Werkstoff, vol. 62, no. 3, pp. 189-196, 2004.

[29] C. W. Oo, M. J. Kassim, and A. Pizzi, "Characterization and performance of Rhizophora apiculata mangrove polyflavonoid tannins in the adsorption of copper (II) and lead (II)," Industrial Crops and Products, vol. 30, no. 1, pp. 152-161, 2009. 

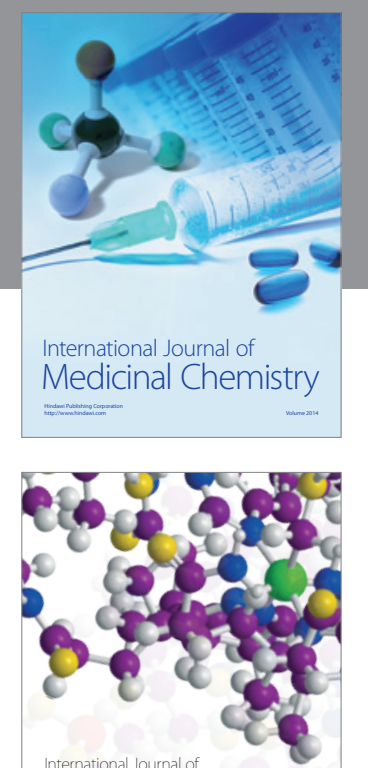

\section{Carbohydrate} Chemistry

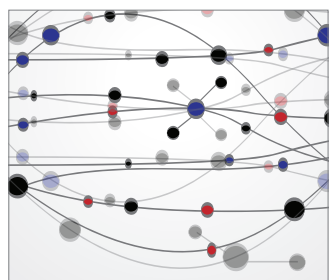

The Scientific World Journal
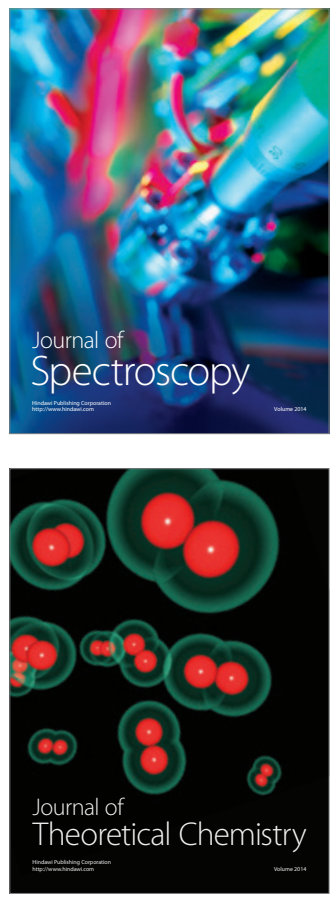
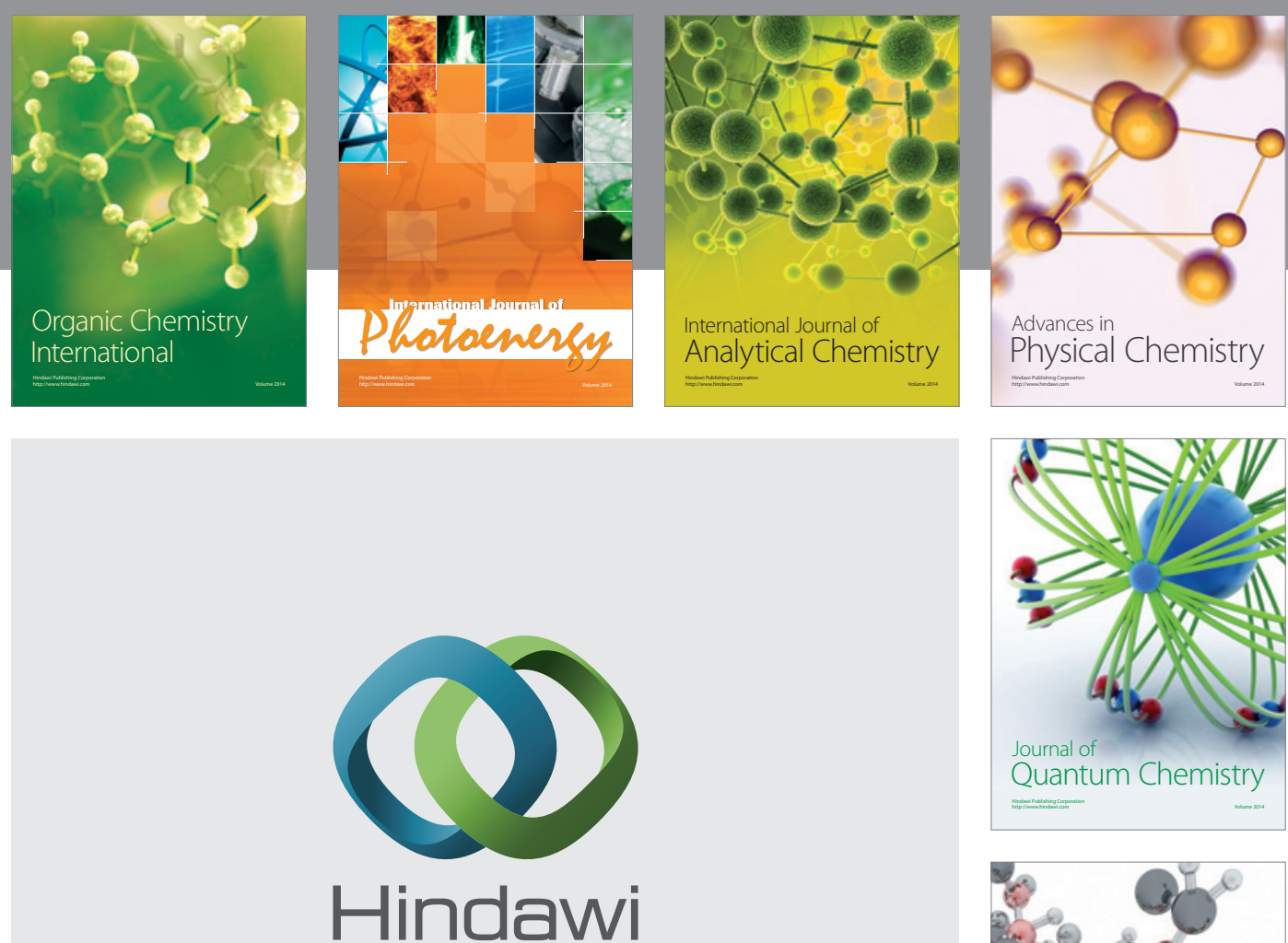

Submit your manuscripts at

http://www.hindawi.com

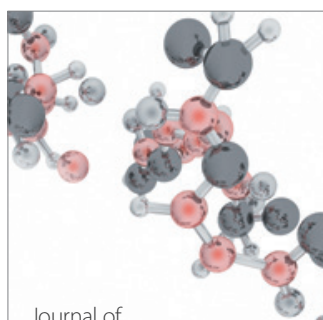

Analytical Methods

in Chemistry

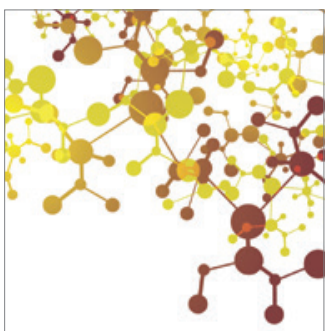

Journal of

Applied Chemistry

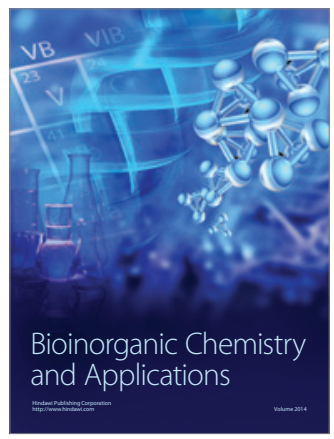

Inorganic Chemistry
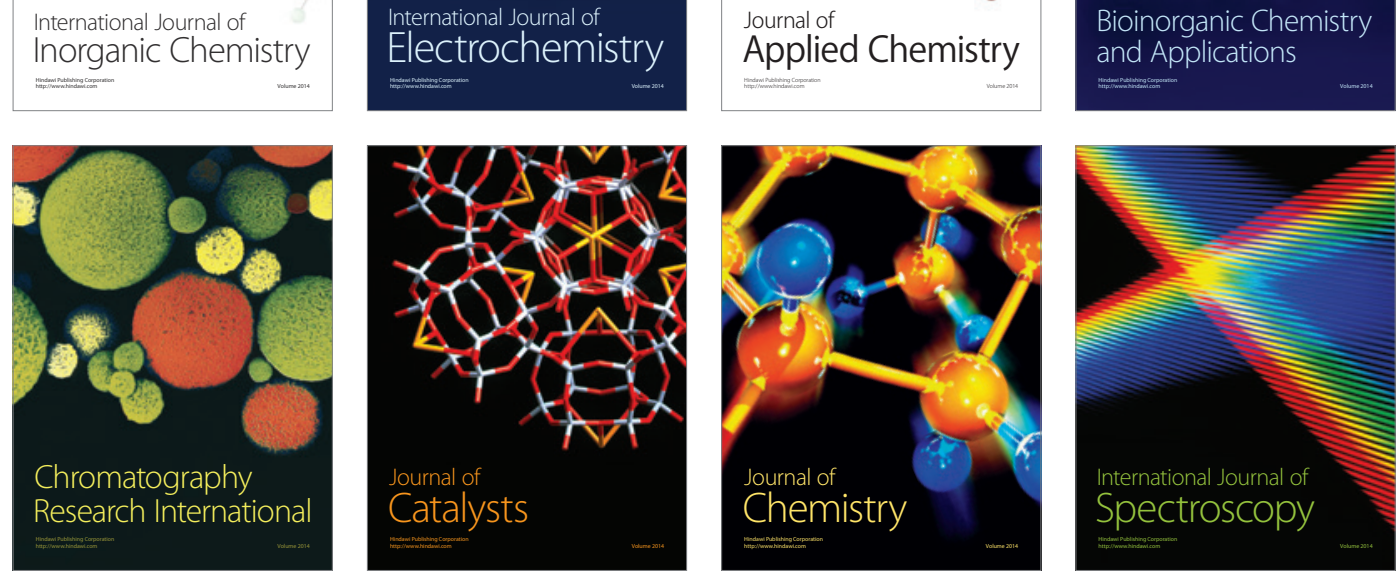